\title{
Beruf und Familie in Lateinamerika
}

\section{Jean Martin}

Dr. med., Mitglied der Redaktion

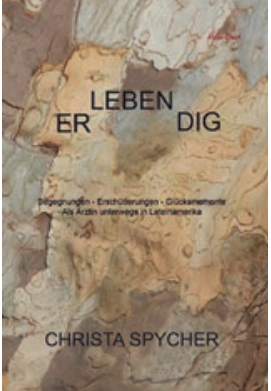

Christa Spycher ER-LEBEN-DIG Als Ärztin unterwegs in Lateinamerika

Mein Buch, 2020 147 Seiten
Christa Spycher hat, gemeinsam mit ihrem Ehemann Peter, den grössten Teil ihrer Karriere der Entwicklungszusammenarbeit gewidmet. Das Ehepaar lebte fast 20 Jahre in Lateinamerika: sechs Jahre in Lima, drei Jahre in einem agroforstwirtschaftlichen Projekt am Ufer des Ucayali, eines grossen Zuflusses des Amazonas, später sieben Jahre in Honduras und Nicaragua - mit zwei Zwischenstationen in Bern. Definitiv in die Schweiz zurückgekehrt sind sie 1998. Während ihr Ehemann in der Direktion für Entwicklung und $\mathrm{Zu}$ sammenarbeit (DEZA) bis zur Pensionierung weiterarbeitete, hat sich die Ärztin Christa Spycher im Gebiet der Familienplanung engagiert. Sie hat eine Tätigkeit im Bereich Frauenfragen wieder aufgenommen, mit der sie sich bereits in Lateinamerika intensiv beschäftigt hatte.

Die Ärztin, Ehefrau eines DEZA-Mitarbeiters und Autorin, die unter schwierigen Bedingungen ihre Fähigkeiten und ihr Engagement zum Wohle ihrer Patientinnen und Patienten eingebracht hat, ist zudem Mutter von drei Töchtern. Das Buch hat mich persönlich berührt, da ich geraume Zeit vor Spychers ebenfalls im peruanischen Amazonasgebiet gearbeitet habe. Später, ums Jahr 2000 herum, bin ich Christa Spycher im Rahmen der Stiftung "Sexuelle Gesundheit Schweiz» wieder begegnet.

\section{Die Erfahrungen von Christa Spycher werden in einer Weise erzählt, die den Menschen und ihren Lebensumständen nahekommt.}

ER-LEBEN-DIG ist eine Erzählung, die sich über drei Jahrzehnte erstreckt. Spycher hat jeweils im Gastland des entsprechenden Entwicklungsprojekts gelebt, in engem Kontakt mit der Bevölkerung, mal in ländlicher, mal in städtischer Umgebung, in oft prekären sozialen Bedingungen und unter verschiedensten politischen Regimes. Die beruflichen, persönlichen und familiären Erfahrungen der Autorin werden in einer Weise erzählt, die den Menschen und ihren Lebensumständen nahekommt; immer empathisch, ohne Schwierigkeiten und gelegentliche Enttäuschungen auszulassen. Es wird nicht sentimental berichtet, sondern es wird konstruktiv offen hinterfragt, wie wir leben und was wir tun.
Eckpunkte dieses Lebensparcours: Spycher hat drei Jahre im Amazonasgebiet verbracht (im öffentlichen Motorboot bis zur nächsten Stadt 12 Stunden flussabwärts, 24 Stunden flussaufwärts wieder nach Hause); soziokulturelles Lernen und Erfahren standen während dieser Zeit im Zentrum. Sie war konfrontiert mit Kargheit und allgegenwärtiger Armut sowie ihren mannigfachen Auswirkungen. In mehreren Ländern hat sie mit Frauen gearbeitet. Auch in Nicaragua, wo die sandinistische Revolution (bevor sie ihre Grundideen aus den Augen verlor) in der Alphabetisierung, in der Kommunalentwicklung und im Kampf gegen häusliche Gewalt bemerkenswerte Erfolge erzielte.

Es gäbe im Buch viele exemplarische Episoden. Ich zitiere nur eine, die mich beschäftigt: «Die 32-jährige Mili besuche ich zuhause, sie ist gehbehindert, und das jüngste ihrer neun Kinder, der 3-jährige Rafito, liegt mit hohem Fieber im Bett [...] Ich frage nach Rosita, ihrer Ältesten, jetzt 13-jährig, die Mili viel Arbeit abnimmt, ihr die Einkäufe besorgt, das Wasser anschleppt, auf die Geschwister aufpasst und sie pünktlich in die Schule schickt. Sie ist nicht da? Hat sie eine Arbeit gefunden? - Mili windet sich etwas (so kommt es mir zumindest vor), bis sie mit ihrer Antwort herausrückt: Rosita lebt jetzt mit einem jungen Polizisten drei Strassen weiter, der ihr dafür Unterwäsche und Seife kauft - im Moment will ich es kaum fassen [...] Jahre später in der Schweiz, als ich mit Gewalt an Frauen und Kindern häufig konfrontiert war und wir uns im multidisziplinären Team vertieft damit befassten, ist mir nach und nach bewusst geworden, wie wenig ich die Realität der Gewalt im Barrio (Armenviertel) effektiv wahrgenommen hatte, mich vor diesem sensitiven Thema instinktiv geschützt und das wahre Ausmass dieses Missstandes gar nicht wirklich hatte erkennen können.»

Aber das Wesentliche, das Christa Spycher erzählt, ist nicht düster, im Gegenteil. Es ist voller Lebendigkeit, menschlicher Wärme, voller Entdeckungsfreude: des neuen Gegenübers, der anderen Kulturen, des Umgangs mit existentiellen Schicksalsschlägen. Die Autorin erzählt mit Talent - der Text ist an keiner Stelle langfädig. Der Erlebnisbericht ist zudem für jene, die sich für eine Tätigkeit in der Entwicklungszusammenarbeit interessieren, äusserst aufschlussreich. 